\title{
Distributed Leadership in a Low-Carbon City Agenda
}

\author{
Azalia Mohamed ${ }^{1, *}$, Zelina Zaiton Ibrahim ${ }^{2}$, Abu Daud Silong ${ }^{3}$ and Ramdzani Abdullah ${ }^{1}$ \\ 1 Department of Environmental Management, University Putra Malaysia, Serdang 43400, Selangor, Malaysia; \\ ramdzani@upm.edu.my \\ 2 Department of Environmental Sciences, University Putra Malaysia, Serdang 43400, Selangor, Malaysia; \\ zelina@upm.edu.my \\ 3 Department of Professional Development and Continuing Education, University Putra Malaysia, \\ Serdang 43400, Selangor, Malaysia; adsz@upm.edu.my \\ * Correspondence: azalia@nre.gov.my; Tel.: +60-3-88861387
}

Academic Editor: Vincenzo Torretta

Received: 30 March 2016; Accepted: 22 July 2016; Published: 26 July 2016

\begin{abstract}
This paper uses Spillane's (2001) theory and Gronn's (2000) concerted efforts approach to examine distributed leadership in a low-carbon city agenda. The main purpose of the paper is to find empirical evidence of a relationship between distributed leadership and the achievement of the agenda. Eight constructs emerged that informed our understanding of distributed leadership dimensions within the low-carbon city framework: vision, organizational framework, organizational culture, consensus, instructional programs, expertise, team leader leadership, and team member leadership. The evidence shows that there is a positive relationship between distributed leadership and the outcome of the low-carbon city agenda, and that a dispersed pattern in distributing leadership is required to enhance community engagement. The findings also suggest that an organizational culture that facilitates multiple sources of leadership may largely contribute to the effectiveness of distributed leadership practices in realizing the low-carbon city agenda.
\end{abstract}

Keywords: distributed leadership; low-carbon city; low-carbon lifestyle; pro-environmental behavior; climate change

\section{Introduction}

The environmental problem related to climate change is an important issue of concern. Scientists (e.g., [1-3]) believe that the unprecedented climate change and increasingly extreme weathers observed in various regions of the world are caused by rapid global warming in the last few decades. Human contributions of heat-trapping greenhouse gases are blamed as the dominant cause of the observed warming [4-6]. Studies (e.g., [7-14]) have reported significant associations between various indicators of lifestyle and resource consumption and consequent carbon emissions. Hence, alterations towards an everyday low-carbon lifestyle are the best solution to effectively tackle the issue [15-17]. The concept of low-carbon lifestyle generally suggests reducing carbon emission from all aspects of living; in which lifestyle strives to be frugal and recyclable towards zero-wastage. The main focus of low-carbon lifestyle is to reduce individuals' carbon footprints and minimize the effects of daily lifestyle in causing devastating climate change. Four routine behavior domains are frequently studied to access individuals' level of low-carbon lifestyle, namely: transportation, food consumption, water and energy use, and waste management (e.g., [18-24]). In low-carbon lifestyle campaigns, government policies and programs encourage citizens to adopt low-carbon behaviors in all daily aspects which include using energy-efficient appliances, buying environmental-friendly products, eating organic and locally grown food, using the car less, and seeking alternatives for short trips, better energy and water management and usage, waste segregation and recycling, and less wasting of food [23]. Collectively, these efforts are aimed specifically at reducing household resource consumption and waste generation. 
Nevertheless, it takes more than the effort of one individual to bring out an impactful change. Recent literatures (e.g., [25-28]) have suggested that more focus should be placed on the community level because individuals will never have full control of their behavior, mainly because most resource consumption and energy-related behaviors are shaped by technical infrastructures that are largely beyond individual's control [29,30]. Furthermore, individuals' decisions are framed by social dilemmas [31] and are rarely made in isolation $[32,33]$. These problems, together with the invisibility of the consequences of their action, lead to a sense of disempowerment that is a major obstacle to adopt low-carbon lifestyles [34]. A community effort in the form of low-carbon community presents at least a partial solution to these problems of individual behavior change. Such communities can be in the forms of geographic communities as well as communities of interest; both are important channels to reach citizens and diffuse low-carbon lifestyle. According to Eyre et al. [35], "communities are an essential part of normalizing and embedding behavioral change" [35] (p. 154). The community must have "the ability to make informed judgements and to take effective decisions regarding the use and management of carbon, through both individual behavior change and collective action" [36] (p. 2).

Middlemiss and Parrish [37] highlighted the roles of grassroots agencies and community structures in creating low-carbon communities. A low-carbon community can be fostered through integrated efforts of various actors at multiple levels [38-41]. Generally, the local authority and multiple agencies that provide support for the community are entrusted with divergent tasks and functions, suggesting the need for interrelated and cohesive efforts spearheaded by an effective leadership [42,43]. The journey towards realizing a low-carbon community requires some form of leadership which spans groups of institutions, each of which have their own leadership structures and processes [44-47]. Individuals at all levels need to provide leadership for change and they need to work together to promote and support change [43,45,47].

Scholars (e.g., $[48,49])$ suggest that the notion of distributed leadership is a good way of considering leadership within and between agencies and communities which are members of the same network, particularly by those who have constructed alliances, support, systems and collaborative cultures. A distributed leadership perspective recognizes that there are multiple leaders [50] and that leadership activities are widely shared within and between organizations [51]. It focuses on the interactions rather than the actions of those in leadership roles and acknowledges the work of all individuals who contribute to leadership practice, whether or not they are formally designated as leaders [52].

There are few clear definitions of distributed leadership. However, literature shows that the works of James Spillane [50,53-55] and Peter Gronn [56,57] have provided the most developed theoretical models of distributed leadership. Spillane [53,54] suggests that distributed leadership is best understood as practice distributed over leaders, followers and their situation and incorporates the activities of multiple groups of individuals [53]. Spillane [54] theorizes two aspects of distributed leadership: the leader-plus aspect and the practice aspect. His theory implies a social distribution of leadership where the leadership function is stretched over the work of a number of individuals and the task is accomplished through the interaction of multiple leaders [50,53,54]. Meanwhile, Gronn [56] focuses on distributed leadership as a concertive action and viewed distributed leadership as a fluid and emergent phenomenon where a group or a network of individuals interacts. He identifies two broad meanings of distributed leadership; one is concerning the aggregated leadership behaviors of multiple leaders, in which leadership is the outcome of distinct but inter-connecting initiatives by a variety of people; while the second focuses on the network of leadership that emerges from the various interactions, where distributed leadership is not the agency of individuals, but conjoint agency, or the concertive labor performed by interdependent organization members [56,57]. In sum, Spillane [54,55] and Gronn [57] view distributed leadership as leadership that is shared amongst organizational members in which decision-making is governed by the interaction of individuals. Gronn [57] suggests that concertive forms of distributed leadership can take the form of spontaneous collaboration, role-sharing, or institutionalized means of working together, such as a committee or team structures. 
Most advocates agree that distributed leadership is not the anti-thesis of top-down, hierarchical leadership (e.g., [52,58-60]) but essentially involves the vertical and lateral dimensions of leadership practice, encompasses both formal and the informal forms. Bennett et al. [58] noted that conceptions of distributed leadership often signal the openness of boundaries and describe its ability to encourage the development of networks rather than relying on traditional hierarchically structured decision-making and communication concept. Nevertheless, many authors (e.g., [60-63]) argue that the leader plus concept or multiple sources of influence [54,62] attached to the notion of distributed leadership, does not imply in any way that formal leaders are now redundant as distributed leadership practice also means actively, brokering, facilitating and supporting the leadership of others [63]. Their findings indicate how some forms of distributed leadership work well with strong leadership from senior leaders, and while bound by aims and values set by superior levels within and beyond the organization $[64,65]$. As distribution of leadership varies in the balance between the amount of control and autonomy that participants are able to exercise, a closer look at team dynamics is necessary in understanding the practice of distributed leadership [66]. Findings by Kets de Vries [67] indicate that distributed leadership promotes effective teamwork where relationships are based on trust, mutual protection and support, open communication, strong sharing of common goals, values and beliefs, and most importantly, all members are empowered to make decisions. Based on case studies concerning leadership in schools, Harris [52] summarizes the common principles that identify distributed leadership to include:

- multiple levels of involvement in decision-making

- it focuses on improving practice or instruction

- it encompasses both formal and informal leaders

- it links vertical and lateral leadership structures

- it is flexible and versatile

- it is fluid and interchangeable.

Meanwhile, Copland [68] sets forth preconditions that must exist in the organization if distributed leadership is to be successful. These include:

- The development of a culture within the organization that embodies collaboration, trust, professional learning and reciprocal accountability.

- Strong consensus regarding the important problems facing the organization.

- A need for rich expertise with approaches to improving knowledge and skills among members of the organization.

A number of studies have demonstrated the powerful relationship between distributed leadership and positive organizational change (e.g., [51,69-74]) and that distributed leadership practice is likely to equate with improved organization performance and outcomes (e.g., [75-77]). However, Spillane and Diamond [50] rightly pointed out that in understanding the effects of distributed leadership, it is not enough to note that leadership is distributed, but more importantly how leadership is distributed. Spillane [54] identifies three types of leadership distribution in co-performance of leadership and management activities: collaborated, collective, and, coordinated. Gronn [57] in his theory of distributed leadership suggests that "concertive actions" of leadership can take the forms of spontaneous collaboration, intuitive working relations, or institutionalized practices. Meanwhile, Gunter [76] argues that describing distributed leadership requires looking at power sources and interactions. Gunter [76] proposes three characterizations of distributed leadership that include authorized, dispersed, and democratic. According to Gunter [76], authorized distributed leadership refers to leadership that is distributed through delegation and empowerment, where formal leaders seek to develop others for leadership roles within the organization. This type of leadership is similar to Woods et al. [66] "delegated leadership" where team members accept the leadership role, but their 
leadership is still dependent on those who hold formal leadership position. The second characterization, dispersed distributed leadership, is where leadership activity takes place "without the formal working of a hierarchy" [76] (p. 52). This reflects that a distributed leadership is an emergent property of a group or network of individuals in which group members pool their expertise, to work together in ways that work best $[56,76,77]$. In democratic distributed leadership, the emphasis for concerted effort goes "beyond the instrumentality of organizational goal" [76] (p. 56) to a wider democratic setting. Gunter [76] suggests that authorized and dispersed categories can provide frames for describing distributed leadership practice and the underlying assumptions about power; democratic, however, should be used as a separate frame because critiques of this setting needs to engage with what is the purpose behind the power.

We found that despite the various claims of positive effects of distributed leadership practices, very few studies that acknowledge the different patterns of leadership distribution (e.g., [59,78-80]) and fewer (e.g., [81,82]) that examined their relations with organizational outcomes. Furthermore, literature shows that the majority of texts produced on distributed leadership were based on examination in the context of school and educational improvement and rarely in community engagement settings (e.g., $[49-62,65,67,68])$. We believe that distributed leadership warrants consideration as a conceptual framework for leadership of intra- and inter-organizational functions such as community engagement. We use an ongoing project called Putrajaya Low-carbon City Initiatives in Malaysia to explore the approach of promoting the low-carbon lifestyle through distributed leadership practices. We posit that dimensions of distributed leadership practices provide a promising tool for understanding of the interactions, the nature and patterns of distributed leadership in this community engagement. Specifically, the aim of the study is to investigate how distributed leadership practices relate to the adoption of low-carbon lifestyle among a sample of community leaders in Putrajaya. In doing so, we intend to examine the relationship between the different patterns of distributed leadership and the low-carbon lifestyle program outcome. We also seek to investigate if there are significant predictors of the level of adoption of low-carbon lifestyles and then determine the contribution of predictor variables towards the variance of the level of adoption.

\section{Distributed Leadership in Practice: Putrajaya Low-Carbon City Initiatives}

In 2009, Malaysia pledged to reduce its carbon dioxide emission to $40 \%$ GDP by 2020 as compared to 2005 levels. The National Green Technology Policy was designed to address climate and energy issues in Malaysia and outlines the country's initiatives on sustainable growth and development. In line with the policy, the Low-Carbon Cities Framework was initiated to provide a framework in the development of sustainable cities and to support sustainable development in Malaysia. Two low-carbon scenarios projects were announced as pioneer green cities. The first is Putrajaya Low-carbon City Initiatives which is implemented at a city level and the other is Sustainable Iskandar Malaysia at a regional level.

Putrajaya Low-carbon City Initiatives focuses on three main themes: low-carbon society, urban heat island, and solid waste management. The themes are equipped with specific environmental targets:

a Low-Carbon Putrajaya: To reduce GHG emission intensity related to energy use by $60 \%$;

b 3R Putrajaya: To reduce the final disposal of solid waste and GHG emission per waste generation by $50 \%$; and

C Cooler Putrajaya: To reduce peak temperature by $2{ }^{\circ} \mathrm{C}$.

Putrajaya Corporation $(\mathrm{PjC})$ as the city council of Putrajaya is the lead agency in the low-carbon city agenda, collaborating with various private and government agencies as well as non-governmental organizations (NGOs). A study was conducted to determine baseline emission levels for the year 2007 and estimates for 2025. The population of Putrajaya in 2007 was 49,452 and is expected to increase to 347,700 in 2025. The total GHG emission in 2007 was estimated at $664 \mathrm{kt} \mathrm{CO}_{2}$ eq with $516 \mathrm{kt} \mathrm{CO}_{2}$ eq emitted from energy use and $148 \mathrm{kt} \mathrm{CO}_{2}$ eq from landfilled solid waste. In 2025, GHG emission is estimated 
to increase seven times to $4186 \mathrm{kt} \mathrm{CO}$ eq if mitigation efforts are not taken. With countermeasures, the emission can be reduced by about $60 \%$ in 2025 to $1780 \mathrm{kt} \mathrm{CO}$ eq. Twelve strategic actions were proposed for implementation by the city council, government departments, private organizations and individuals in achieving the Low-carbon City status (see Table 1).

Table 1. Environmental targets and strategic actions in Putrajaya Low-carbon City Initiatives.

\begin{tabular}{cll}
\hline Environmental Targets & & \multicolumn{1}{c}{ Action } \\
\hline & 1. & Integrated City Planning and Management \\
& 2. & Low-Carbon Transportation \\
Low-Carbon Putrajaya & 3. & Cutting Edge Sustainable Buildings \\
& 4. & Low-Carbon Lifestyle \\
& 5. & More and More Renewable Energy \\
& 6. & The Green Lungs of Putrajaya \\
\hline \multirow{2}{*}{ Cooler Putrajaya } & 7. & Cooler Urban Structure and Buildings \\
& 8. & Community and Individual Actions to Reduce Urban Temperature \\
\hline \multirow{2}{*}{ 3R Putrajaya } & 9. & Use Less Consume Less \\
& 10. & Think Before You Throw \\
& 11. & Integrated Waste Treatment \\
\hline Cross Category & 12. & Green Incentives and Capacity \\
\hline & & Source: Putrajaya Green City, 2012.
\end{tabular}

Public participation and community actions are encouraged through Actions 2, 4, 9 and 10 which call for a change in lifestyle towards reducing energy consumption and reducing the volume of solid waste. This study examines the realization of the low-carbon city agenda through communities' adoption of a range of low-carbon practices which include waste segregating and recycling, prioritizing environmental friendly products, limiting usage of motorized vehicles, and better management of electricity and water resources. We focus on assessing the communities' adoption of the low-carbon lifestyle and investigating its relations with the practice of distributed leadership in the low-carbon city setup. We intend to find answers for the following research questions: What is the relationship between community leaders' perceptions on the dimensions of distributed leadership and their adoption of low-carbon lifestyle? Are there any (among the distributed leadership dimensions) significant predictors of the level of low-carbon lifestyle? The research framework is depicted in Figure 1.

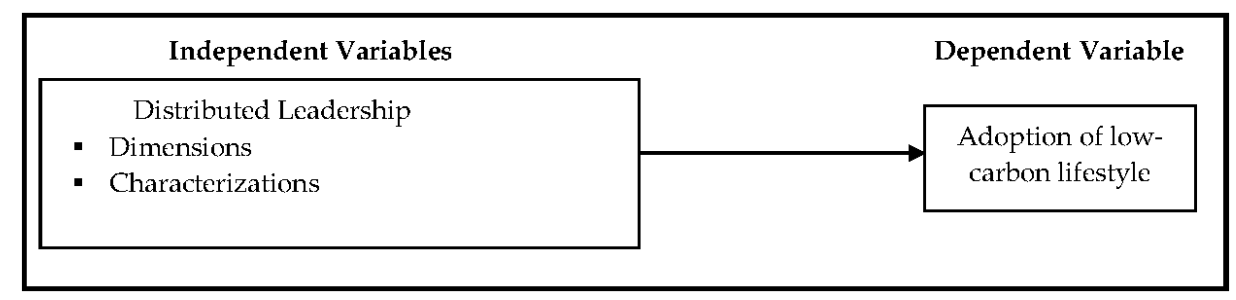

Figure 1. Research Framework.

\section{Method}

A methodological triangulation approach was applied to facilitate this mixed method study where a few qualitative interviews were conducted to supplement a major quantitative study. The data from the qualitative interviews were primarily utilized as basis to design tools for the quantitative method as well as enhance and illustrate the results. The process of data collection in this study consisted of three methods namely focus group discussions, structured interviews, and a questionnaire survey.

\subsection{Focus Group Discussion}

A focus group discussion was conducted in the earlier part of this study to set the framework and to identify items for the quantitative study. The objective of the focus group discussion was to gain 
an understanding of public perspective on the topic. Twelve representatives of residents' association committees (RACs) in Putrajaya participated in the focus group discussion. The participants were divided into three groups. At the end of the session, the group presented results of their discussions. The researcher then classified issues presented by the respondents to three categories. The issues are: (i) directives and guidelines on low-carbon practices; (ii) facility and support for low-carbon lifestyle; (iii) inclusion of RACs in the planning and implementation of the low-carbon programs.

The focus group discussion has also identified six agencies involved in the Putrajaya low-carbon city initiative. The agencies are: Putrajaya Corporation (PjC), Ministry of Energy, Green Technology and Water (KeTTHA), Ministry of Urban Wellbeing, Housing and Local Government (KPKT), Ministry of Education (MOE), Ministry of Natural Resource and Environment (NRE), and Alam Flora. In summary, the focus group discussion has contributed to our understanding of the low-carbon lifestyle issues particularly the public's perception in Malaysia.

\subsection{Structured Interviews}

In this study, face to face interview sessions were held with community leaders and officers of agencies involved in the low-carbon city program. The interviewees were recruited via chain referral method. Four community leaders were individually interviewed. A set of open-ended questions was used as the interview guidelines, asking, for example, to describe the management of low-carbon lifestyle programs in their RACs and what they perceive as important issues in ensuring the success of low-carbon lifestyle agenda. Each session took approximately 30 to $45 \mathrm{~min}$. In addition, insights were also gathered from face to face interviews of officers from agencies involved in the low-carbon community programs, i.e., two officers from Town Planning Unit in PjC, one officer from KeTTHA, and an elected community representative in the Putrajaya Green City Steering Committee. However, we were unable to interview any representative from KPKT, MOE, NRE, and Alam Flora. The interviews were recorded and reviewed in isolating the variables to be included in the research framework. This involved recognizing commonalities and regularities in the responses where themes that emerged were categorized and analyzed for consistency [83].

The statements of the participants were analyzed for mentioning of common key words or its associated descriptions which were then scored based on their frequencies. Based on analysis of the interview transcripts, 10 keywords were most frequently mentioned, i.e., vision, organizational framework, organizational culture, consensus, instructional programs, expertise, team leader leadership, team member leadership, authorized leadership, and dispersed leadership. Table 2 provides illustrative quotes from the interviews. The keywords were then used as dimension and characterizations of distributed leadership and used to construct the survey instrument for the quantitative part of the research.

Table 2. Examples of quotes from interview sessions for (a) dimensions and (b) patterns of distributed leadership.

\begin{tabular}{ll}
\hline Category & \multicolumn{1}{c}{ Quotes from Respondents Surveyed } \\
\hline (a) Dimension \\
\hline "I'm not sure what the local authority hopes to achieve through their low-carbon city \\
agenda, but as far as my RAC's concern, our only focus is to ensure that our \\
neighborhood is kept clean and litter free. We were not involved in the planning \\
process but I suppose the master plan does include us (RACs)." \\
"They should have included us (in the planning). After all, we (RACs) are the ones \\
Who will be conducting the programs in the community." \\
"A few of us attended a workshop about this matter a few years ago. A few agencies \\
were also present. We discussed about the programs, we gave our views and \\
suggestions especially on how our community can take part in the program." \\
"My RAC Chairman has been involved in the low-carbon city program since it started. \\
He updates us with the latest information."
\end{tabular}


Table 2. Cont.

\begin{tabular}{|c|c|}
\hline Category & Quotes from Respondents Surveyed \\
\hline $\begin{array}{l}\text { Organizational } \\
\text { framework }\end{array}$ & $\begin{array}{l}\text { "There should be more RAC representatives in the Low-carbon City Council." } \\
\text { "I'm not sure where my RAC fit in this low-carbon city framework." } \\
\text { "There are many agencies involved in the low-carbon city program, each has specific } \\
\text { focuses and functions but they are all connected in the network." }\end{array}$ \\
\hline $\begin{array}{l}\text { Organizational } \\
\text { culture }\end{array}$ & $\begin{array}{l}\text { "The low-carbon city agenda should be carried by the whole community, not just the } \\
\text { local authority, nor the agencies. Community leaders must be encouraged to take } \\
\text { leadership roles in low-carbon initiatives. If community leaders are not empowered, } \\
\text { the program will not succeed." } \\
\text { "We are encouraged to collaborate with other RACs. One of our shared projects is the } \\
\text { 'Kitchen Garden'. We have regular meetings to discuss and properly plan for the } \\
\text { project. We not only share resources and responsibilities but we also decide together on } \\
\text { future projects." } \\
\text { "We have close relationships with a few RACs. We exchange views and help } \\
\text { one another. I like asking for their opinion because we usually face the same } \\
\text { problems in our community." }\end{array}$ \\
\hline Consensus & $\begin{array}{l}\text { "Sometimes they ask for our opinion, but most of the time we just receive instructions." } \\
\text { "Only the Chairman knows what was discussed or decided in the meetings with } \\
\text { the local authority." } \\
\text { "Most of the time they will call us to inform us of the coming programs." }\end{array}$ \\
\hline $\begin{array}{c}\text { Instructional } \\
\text { program }\end{array}$ & $\begin{array}{l}\text { "We can propose our own programs to the local authority." } \\
\text { "The agencies gave us instructions to implement the programs in our communities." } \\
\text { "We sometimes improvise to suit our community." }\end{array}$ \\
\hline Expertise & $\begin{array}{l}\text { "We have managers, engineers and many other professionals in our community. } \\
\text { They are more than able to lead; perhaps much better than the elected committee, but } \\
\text { most say that they are too busy with work." } \\
\text { "There are a few knowledgeable persons in the community. We encourage them to join } \\
\text { us in coordinating activities. } \\
\text { "Some households are more diligent than others in the practice of recycling. They are } \\
\text { good role models." }\end{array}$ \\
\hline $\begin{array}{l}\text { Team leader } \\
\text { leadership }\end{array}$ & $\begin{array}{l}\text { "The local authority knows about the problems that we face in implementing } \\
\text { the programs." } \\
\text { "They provide us with the budget and materials." } \\
\text { "Frankly, I have never met with any of the officers. They usually communicate with } \\
\text { the Chairman." }\end{array}$ \\
\hline $\begin{array}{l}\text { Team member } \\
\text { leadership }\end{array}$ & $\begin{array}{l}\text { "Leadership in the RACs is equally important. RACs must be able to unify community } \\
\text { members, get them to work together." } \\
\text { "They (RACs) must lead, mentor and inspire others." } \\
\text { "They should not expect the Chairman to do everything, other RAC members must } \\
\text { step up and offer to lead." }\end{array}$ \\
\hline & (b) Characterization \\
\hline Authorized & $\begin{array}{l}\text { "As management we decide on certain matters about the programs but we let the } \\
\text { RACs take charge of their implementation" } \\
\text { "We identify the RAC and approach the Chairman to coordinate these activities." }\end{array}$ \\
\hline Dispersed & $\begin{array}{l}\text { "We share materials and discuss strategies with other RACs" } \\
\text { "We encourage the community to initiate their own programs." }\end{array}$ \\
\hline
\end{tabular}

\subsection{Survey}

In this study, survey method was used to gather empirical data in examining the relationship between the variables in order to answer the research questions. A brief description of the survey sample, sampling process, instrument, and analysis conducted are provided below.

\subsubsection{Sample}

The study was conducted in Putrajaya, the Federal Administrative Centre of Malaysia. We noted that leadership in the Putrajaya low-carbon city setting moves among the local authority, related 
government agencies, community leaders, as well as community members. We chose community leaders specifically the elected leaders in residents' association committees (RACs) as the target population in this study. This group of leaders was chosen as unit of analysis based on several reasons: RACs are the focal point in disseminating the green city agenda to the public and as elected representatives, RACs are the eyes and the ears of the community they represent. Leaders of RACs are most knowledgeable about the community and highly involved, and therefore most responsible for the success of the change effort [84]. Moreover, being closely connected to the community has given RACs leaders vast opportunities to influence the opinions, attitudes, beliefs, motivations, and behaviors of others. The opinions and behaviors of these leaders will greatly contribute to the community's positive perception and subsequent adoption of low-carbon lifestyle.

There are 102 residents' associations in Putrajaya, which are categorized into two groups based on the types of houses: landed property or apartment. Seventy-eight of the resident associations are residents of apartments while the remaining 24 are residents of landed properties. The organizational structures of these RACs were almost similar, consisted of Chairman, Secretary, Treasurer and Committee Members. The number of members in each RACs in Putrajaya varies from 10 to 20. The population was determined through contacts with all chairmen before the implementation of the survey and a total of 1500 persons were recorded.

\subsubsection{Sample Size}

A sample size of 402 community leaders was selected using a proportionate stratified random sampling technique. The sample size was determined through Krejcie and Morgan [85] method and took into consideration the statistical analyses planned.

\subsubsection{Sampling}

This study employed the multistage sampling technique which selects sample in stages, that is, taking samples from the samples. This sampling technique was undertaken because a complete list of community leaders was not available and would be difficult to compile. Based on a list of 102 RACs provided by Putrajaya Corporation ( $\mathrm{PjC}$ ), the RACS were stratified into two house types (landed, and apartment) and sampled. This technique is commonly used in research studies where the population consists of subgroups and each of these subgroups must be investigated to increase the accuracy and reliability of the results. Hence, stratified sampling was employed to ensure a balanced proportion of the subgroups were included in the study and the representativeness of the results.

In phase 1, all 102 chairmen of RACs were surveyed. Based on the ratio of 24:78 for landed to apartment house type, 51 RACs were randomly selected for Stage 2 sampling which include 12 RACs from landed and 39 from apartment types. Complete lists of RAC committee members were obtained from the Chairmen of the selected RACs. Next, six names were randomly selected from each of the 51 RACs. Starting with the first name, we proceeded to take every 3rd name on the lists. The selected community leaders were contacted and invited to participate in the survey. Another name was drawn from the lists to replace names that the researcher was unable to contact. In phase 2, a total of 300 committee members were surveyed. In both phases, each community leaders were briefed and given a survey kit containing a set of self-administered questionnaire. The questionnaires were collected within one or two days after the sessions.

\subsubsection{Research Instrument}

Items included in the Adoption of Low-carbon Lifestyle Survey (ALLS) instrument were developed based on literature review, focus group discussion and interview sessions. The survey instrument was designed to examine ten variables which include eight dimensions of distributed leadership (i.e., vision, organizational framework, organizational culture, consensus, instructional programs, expertise, team leader leadership, team member leadership) and two characterizations of leadership distribution (i.e., authorized, dispersed) These distributed leadership dimensions and 
characterizations are supported by Spillane's $[53,54]$ theory (leader, follower and situation) and Gronn's [57] additive or multiple leadership approach, as well as extensions of the theories by other authors such as Leithwood [72-74], Harris [51,52,70,77,80], Copland [68], Woods [66], and Gunter [76]. Attributes related to each of the eight dimensions and the two characterizations were considered for use in the questionnaire. The definitions of the dimensions and characterizations as well as the scope covered by the attributes are provided in the next section.

i Vision: Survey items in this dimension refer to the collective beliefs of the community leaders concerning the low-carbon city agenda. Community leaders provide input in setting the low-carbon city's vision, and goals. Community leaders can articulate the city's vision. The RAC's goals are aligned with the city's goals.

ii Organizational Framework: Organizational framework refers to the structure of the low-carbon city framework which includes the agencies, RACs and individuals associated with it and the structural connections between them. The attributes in this dimension relate to opportunities for RACs and community leaders to assume leadership roles and participate in decision making as well as make meaningful contributions to the low-carbon city initiatives.

iii Organizational culture: Organizational cultures are the intangible principles that define the low-carbon community climate. Attributes in this dimension relate to community leaders being encouraged by the low-carbon city administration to take up leadership roles in the community's low-carbon initiatives, community members collaborate to solve problems and discuss instructional strategies with one another and the agencies governing the low-carbon city agenda. The attributes also relate to community leaders feel respected by their peers and the administrator.

iv Consensus: Consensus means that the administrator and community leaders are in agreement in the programs. The attributes in this dimension relate to community leaders role in the decision making process.

$\mathrm{v}$ Instructional program: Instructional program refers to guidelines and instructions pertaining to the implementation of low-carbon initiatives. The attributes in this dimension relate to community leaders' involvement in setting the guidelines for their community and authority of community leaders to make instructional changes based on the specific needs and suitability in their respective community.

vi Expertise: Expertise refers to the skilled and knowledgeable individuals in the RACs to lead the community's low-carbon initiatives. The attributes in this dimension relate to how expertise is managed and coordinated in order to leverage its potential.

vii Team leader leadership: Team leader refers to the program administrator specifically the local authority and other related agencies in the low-carbon city implementation framework. The attributes in this dimension demonstrate the level of leadership by the team leader, the team leader's participation in RAC meetings and RAC activities, the team leader's knowledge about the program, and the team leader's leadership in improving the program outcomes.

viii Team member leadership: Team member refers to members of residents' association committees. Team member leadership refers to leadership demonstrated by team members. The survey items in this dimension relates to team members' interest to serve in low-carbon city leadership roles, opportunities for team members or other members of the community to influence improvement in the program outcomes.

ix Authorized distributed leadership: Authorized distributed leadership takes place when formal leaders distribute work and work is accepted as a means of empowerment [86]. This type of leadership is evident in a hierarchical structure such as in teams and committees. The attributes in this leadership practice relate to team members receiving instructions from team leader to make decisions and have control on specified areas. Team leader allows members to initiate collaborations with one another and also with other RACs but team leader maintains the ultimate power to lead. 
x Dispersed distributed leadership: This characterization refers to leadership activity that happens without the formal working of hierarchy, where leadership is more bottom-up, team members and skilled individuals work as empowered and self-led teams. The attributes in this leadership practice relate to relative freedom to interact and lead, where knowledgeable and skilled individuals either individually or collaboratively lead the practice.

Below we outline the content of the ALLS and the scales used for the purpose of the present study: The first section of the ALLS collects demographic information, i.e., age, gender, educational attainment, type of house, years living in Putrajaya. Meanwhile, the second section was designed to assess the respondents' low-carbon lifestyle. In this section, a total of 25 statements were employed to assess respondents' low-carbon practices inside and outside the home. Respondents were asked to report how often they performed practices under the five low-carbon lifestyle dimensions, i.e., waste segregating and recycling, efficient usage of electricity, efficient usage of fuel, prioritizing environment-friendly products, and frugal usage of water. The questionnaire utilized a discrete five point (1-5) Likert scale ranging from "never" to "all the time" ( $1=$ never; $2=$ once a while (less than once a month); $3=$ sometimes (once or twice a month); $4=$ frequently (several times per week); $5=$ all the time.

Questions in this section utilized a continuous four-point Likert scale that do not include any neutral answers, ranging from "strongly disagree" to "strongly agree" $(1=$ strongly disagree to $4=$ strongly agree). Consequently, the fourth section of ALLS focused on assessing the respondents' perceptions of the distribution of leadership in their RACs based on eight dimensions particularly: visions, organizational framework, organizational culture, consensus, instructional programs, expertise, team leader leadership, and team member leadership. Meanwhile, questions pertaining to the characterizations of leadership distribution were embedded in each dimension. The respondents were asked to indicate their agreement on the 42 statements given using a continuous four-point Likert scale ranging from "strongly disagree" to "strongly agree" ( 1 = strongly disagree; 2 = disagree; $3=$ agree; $4=$ strongly agree). The ALLS instrument was subjected to two field-test and examined for reliability before it was utilized in the survey. The Cronbach's alpha ranged from the lowest 0.70 for "efficient usage of electricity" to the highest 0.91 for "commitment" which indicated the reliability of the survey.

\subsubsection{Data Analysis}

From the 402 RAC leaders surveyed, a total of 304 returned completed questionnaires. The respondents varied with regards to demographics. The respondents consisted of $283(93.1 \%)$ males and $21(6.9 \%)$ females. The age of the community leaders ranges from 29 to 70 , with a mean of $47.9(S D=9.2)$. The data were analyzed using a series of statistical analyses which include descriptive statistics, correlation statistics, multiple regression, and moderated multiple regression analyses. Prior to the application of statistical procedures, an exploratory data analysis (EDA) was applied to check for conformation with the basic assumptions in terms of normality and also to ascertain that there was no issue of multicollinearity. We produced a correlation matrix for the attribute and contextual variables to gain initial insight into how our research variables are related. A multiple linear regression analysis was used to quantify the contributions of the independent variables towards the variance in the adoption of low-carbon lifestyle. We employed hierarchical method of regression in which each independent variable was entered into the discriminant equation, one at a time, to regress on the criterion variable, i.e., the adoption of low-carbon lifestyle.

\section{Results}

\subsection{Exploratory Data Analysis}

Based on the multivariate normality assessment, the data for each construct items was normally distributed because no skewness value was greater than 2.0 and kurtosis values were less than 7.0. According to Tabachnick and Fidell [87], the data distribution is considered as normal when skewness 
value is less than 2.0 and kurtosis value is less than 7.0. An examination for potential multicollinearity problems indicated that all tolerance values were greater than 0.1 and VIF values were below 10, indicating that multicollinearity among the investigated variables is not a problem in this study.

\subsection{Descriptive Statistics}

An examination of community leaders' responses on subscales with a range from 1 to 5 , revealed that community leaders adopt low-carbon lifestyle at a moderate level $(M=2.83, S D=0.51)$. Moderate mean scores obtained for each dimensions of distributed leadership indicate community leaders perceived that leadership was moderately distributed. This was measured in terms of visions $(M=2.99, S D=0.35)$, organizational framework $(M=2.56 ; S D=0.38)$, organizational culture $(M=2.70$, $S D=0.41)$, consensus $(M=2.79, S D=0.35)$, instructional programs $(M=2.33, S D=0.44)$, expertise $(M=2.59, S D=0.44)$, team leader leadership $(M=2.44, S D=0.43)$, and team member leadership $(M=2.64, S D=0.44)$. The results also revealed that, based on the means on subscales with a range from 1 to 5 , community leaders perceived moderate levels of authorized distributed leadership $(M=2.75$, $S D=0.34)$ and dispersed distributed leadership $(M=2.70, S D=0.37)$. Results from paired samples T-test indicate that the means for authorized distributed leadership was significantly higher compared to the means for dispersed distributed leadership scores. This means that the community leaders perceived that the characteristics of distribute leadership practiced in the low-carbon city initiative is more prominently authorized distributed leadership.

\subsection{Correlation Analyses}

An examination of the correlations, as displayed in Table 3, suggests that there are significant positive correlations between dimensions of distributed leadership and community leaders' adoption of low-carbon lifestyle. Results from the analysis for each dimension indicate positive correlations between all eight dimensions with community leaders' adoption of low-carbon lifestyle. The magnitude showed the range of correlation coefficient from 0.27 to 0.68 indicating a weak to moderate positive linear relationships. According to Guildford's Rule of Thumb [88], the $r$ value of 0.4 to 0.7 indicates a moderate positive linear relationship, while $r$ value of $0.70-0.90$ indicates a strong linear relationship.

Table 3. Correlation matrix analysis of the adoption of low-carbon lifestyle and dimensions of distributed leadership, $(n=304)$.

\begin{tabular}{|c|c|c|c|c|c|c|c|c|c|c|}
\hline & Variable & 1 & 2 & 3 & 4 & 5 & 6 & 7 & 8 & 9 \\
\hline 1 & $\begin{array}{l}\text { Adoption of } \\
\text { low-carbon lifestyle }\end{array}$ & 1.00 & & & & & & & & \\
\hline 2 & $\begin{array}{l}\text { Organizational } \\
\text { culture }\end{array}$ & $0.680^{* *}$ & 1.00 & & & & & & & \\
\hline 3 & Expertise & $0.668^{* *}$ & $0.748^{* *}$ & 1.00 & & & & & & \\
\hline 4 & Vision & $0.345 * *$ & $0.364 * *$ & 0.368 ** & 1.00 & & & & & \\
\hline 5 & $\begin{array}{l}\text { Team member } \\
\text { leadership }\end{array}$ & $0.422 * *$ & $0.418^{* *}$ & $0.555^{* *}$ & $0.519 * *$ & 1.00 & & & & \\
\hline 6 & $\begin{array}{l}\text { Institutional } \\
\text { framework }\end{array}$ & $0.411^{* *}$ & $0.574 * *$ & $0.453 * *$ & $0.356^{* *}$ & $0.448^{* *}$ & 1.00 & & & \\
\hline 7 & Consensus & $0.314^{* *}$ & $0.481^{* *}$ & $0.325^{* *}$ & $0.339 * *$ & $0.444^{* *}$ & $0.585^{* *}$ & 1.00 & & \\
\hline 8 & $\begin{array}{l}\text { Team leader } \\
\text { leadership }\end{array}$ & $0.274^{* *}$ & $0.444^{* *}$ & $0.354^{* *}$ & $0.464^{* *}$ & $0.624^{* *}$ & $0.504^{* *}$ & $0.572 * *$ & 1.00 & \\
\hline 9 & $\begin{array}{l}\text { Instructional } \\
\text { programs }\end{array}$ & $0.269 * *$ & $0.448^{* *}$ & 0.363 ** & $0.344^{* *}$ & $0.451 * *$ & $0.471^{* *}$ & $0.498 * *$ & $0.717^{* *}$ & 1.00 \\
\hline
\end{tabular}

The results indicate that there is moderate positive linear relationship between adoption of low-carbon lifestyle and four dimensions of leadership, i.e., organizational culture $(r=0.68, p=0.00)$, 
expertise $(r=0.67, p=0.00)$, team member leadership $(r=0.42, p=0.00)$ and organizational framework $(r=0.41, p=0.00)$. Meanwhile, results of the correlation analyses also suggest that adoption of low-carbon lifestyle was positively related to vision $(r=0.35, p=0.00)$, consensus $(r=0.31, p=0.00)$, team leader leadership $(r=0.27, p=0.00)$ and instructional programs $(r=0.27, p=0.00)$. However, the relationships among the variables were weak, albeit been significant.

In addition, the correlation examination between the characterizations and adoption of low-carbon lifestyle (see Table 4) indicates a moderate positive relationships between dispersed distributed leadership characterizations and community leaders' adoption of low-carbon lifestyle, $(r=0.44$, $p=0.00$ ). Results of the examination also suggest weak positive relationship between adoption of low-carbon lifestyle and authorized distributed leadership $(r=0.27, p=0.00)$. The magnitude of the correlation coefficients indicates a stronger correlation between dispersed patterns of distributed leadership with community leaders' adoption of low-carbon lifestyle compared to an authorized pattern.

Table 4. Correlation matrix analysis of the adoption of low-carbon lifestyle and characterizations of distributed leadership, $(n=304)$.

\begin{tabular}{|c|c|c|c|c|}
\hline & Variable & 1 & 2 & 3 \\
\hline 1 & Adoption of low-carbon lifestyle & 1.00 & & \\
\hline 2 & Authorized & $0.273^{* *}$ & 1.00 & \\
\hline 3 & Dispersed & $0.435^{* *}$ & $0.451^{* *}$ & 1.00 \\
\hline
\end{tabular}

\subsection{Multiple Regression Analyses}

Table 5 shows regression results. We created four successive models to predict the adoption of low-carbon lifestyle. Results of the analyses indicate that all of the models are statistically significant. Model 1 includes organizational culture and expertise. The coefficient on the organizational culture was positive and highly significant, as was the coefficient on expertise. The coefficient of determination $\left(R^{2}\right)$ for Model 1 was 0.520 while the adjusted $R^{2}$ was 0.516 , indicating that approximately $51.6 \%$ of the variance of the community leaders' adoption of low-carbon lifestyle could be accounted for by the linear combination of organizational culture and expertise. We found that the addition of more predictors to the regression equation did not contribute markedly to explained variance of the overall model, Model 2 (organizational culture, expertise, team member leadership, instructional program): explained variance $=52.3 \%$; Model 3 (organizational culture, expertise, team member leadership, instructional program, team leader leadership, vision): explained variance $=52.7 \%$; Model 4 (organizational culture, expertise, team member leadership, instructional program, team leader leadership, vision, organizational framework, consensus) explained variance $=52.4 \%$.

An examination on the full model (Model 4) showed that a linear combination of vision, organizational framework, organizational culture, consensus, instructional programs, expertise, team leader leadership and team member leadership scores was significantly related to adoption of low-carbon lifestyle, $F((8,295)=42.70, p<0.01)$. Therefore, the regression equation for predicting the community's adoption of low-carbon lifestyle was:

Predicted low-carbon lifestyle adoption $=0.076 \times$ Vision $+0.023 \times$ Organizational framework $+0.443 \times$ Organizational culture $+0.003 \times$ Consensus $-0.042 \times$

Instructional programs $+0.288 \times$ Expertise $-0.116 \times$ Team leader leadership +0.118

$\times$ Team member leadership +0.137 
Table 5. Summary of hierarchical regression analyses for variables predicting community leaders' adoption of low-carbon lifestyle $(N=304)$.

\begin{tabular}{|c|c|c|c|c|c|c|c|c|c|c|c|c|}
\hline \multirow[b]{2}{*}{ Variable } & \multicolumn{3}{|c|}{ Model 1} & \multicolumn{3}{|c|}{ Model 2} & \multicolumn{3}{|c|}{ Model 3} & \multicolumn{3}{|c|}{ Model 4} \\
\hline & B & SE B & $B$ & B & SE B & $B$ & B & SE B & $B$ & B & SE B & $B$ \\
\hline (Constant) & $0.368^{* *}$ & 0.139 & & $0.326^{*}$ & 0.157 & & 0.161 & 0.193 & & 0.137 & 0.214 & \\
\hline Organizational culture & 0.507 & 0.075 & $0.409 * *$ & 0.550 & 0.078 & $0.444^{* *}$ & 0.562 & 0.079 & $0.454^{* *}$ & 0.549 & 0.086 & 0.443 ** \\
\hline Expertise & 0.423 & 0.070 & $0.362 * *$ & 0.362 & 0.077 & $0.310^{* *}$ & 0.335 & 0.078 & $0.287^{* *}$ & 0.337 & 0.079 & $0.288^{* *}$ \\
\hline Team member leadership & & & & 0.124 & 0.060 & $0.105^{*}$ & 0.143 & 0.071 & $0.121 *$ & 0.139 & 0.072 & 0.118 \\
\hline Instructional programs & & & & -0.105 & 0.055 & -0.090 & -0.046 & 0.068 & -0.039 & -0.050 & 0.069 & -0.042 \\
\hline Team leader leadership & & & & & & & -0.133 & 0.080 & -0.112 & -0.138 & 0.082 & -0.116 \\
\hline Vision & & & & & & & 0.114 & 0.071 & 0.077 & 0.112 & 0.071 & 0.076 \\
\hline Organizational framework & & & & & & & & & & 0.031 & 0.075 & 0.023 \\
\hline Consensus & & & & & & & & & & 0.004 & 0.080 & 0.003 \\
\hline F statistic & & 162.752 & & & 83.943 & & & 57.241 & & & 42.698 & \\
\hline$R^{2}$ & & 0.520 & & & 0.529 & & & 0.536 & & & 0.537 & \\
\hline Adjusted $R^{2}$ & & 0.516 & & & 0.523 & & & 0.527 & & & 0.524 & \\
\hline
\end{tabular}

${ }^{*} p<0.05 ;{ }^{* *} p<0.01$ 
However, the results indicated that only two variables were significant predictors of community's adoption of low carbon lifestyles namely organizational culture and expertise, both with $p<0.01$. We also noted that the standardized regression coefficient $(\beta)$ which indicate the relative importance of the predictors in predicting community's adoption of low-carbon lifestyle was highest for organizational culture and expertise in all four models. This suggests that organizational culture was the strongest contributor to the equation, followed by expertise. We then conducted stepwise regression method to sift through the potential variables in selecting the best subset in the prediction model. From the analysis, the best prediction model for the adoption of low-carbon lifestyle in standard score was:

Predicted low - carbon lifestyle adoption $=0.409 \times$ Organizational culture $+0.362 \times$ Expertise +0.368

The total amount of variance of the criterion variable that was predictable from the two predictor variables was $52.0 \%$ and the adjusted $R^{2}$ was $51.6 \%$. Therefore, the final regression model was successful in explaining approximately $51.6 \%$ of the adjusted variance in community's adoption of low-carbon lifestyle.

\section{Discussion}

The current research findings highlight the importance of leadership in ensuring the success of diffusion and adoption of the new lifestyle by the community. In general, the findings from this study are consistent with previous studies (for example, [35,89-91]) which concluded that leadership is an important driver of community emission reduction efforts. In this scenario, leadership revolves around the activity and the act of influencing in realizing the low-carbon city objectives. To stimulate individual citizens' behavior change, leaders must take the lead by adopting a model consisting of four E's that is to "exemplify", "enable", "engage", and "encourage" low-carbon behavior [90]. The results of this study indicated that about $85 \%$ of the community leaders have reported moderate to high level of low-carbon lifestyle. This is perhaps not a satisfactory achievement considering that the community leaders are fully aware of the programs due to their involvement in the RAC committees. This suggests that it will take a longer time for the low-carbon lifestyle agenda to trickle down and be adopted by the community.

Scholars and practitioners (e.g., [92-95]) suggest that the style of leadership adopted is particularly important in achieving organizational goals and in evoking performance among subordinates. This study followed the path of authors (e.g., [53,57]) who examined leadership from a distributed perspective with the focus on the leadership practices that take shape from the interaction of leaders, followers, and their situation. One of the most noteworthy aspects of our analysis is the large proportion of the variance in the adoption of low-carbon lifestyle (51.6\%) that is accounted for by the dimensions reflecting distributed leadership. These dimensions portray distributed leadership practices and variations in the low-carbon city agenda. The present study extends our understanding of the underlying patterns of program effectiveness associated with distributed leadership practices (e.g., $[51,73,96,97])$. We created a hypothesis that includes eight dimensions of distributed leadership (vision, organizational framework, organizational culture, consensus, instructional program, expertise, team leader leadership, team member leadership) extracted from Spillane's theory $[53,54]$ and Gronn's multiple leadership approach [57] as well as from the literature on this topic.

In this study, we examined the relationship between each of the dimensions and low-carbon city outcomes. The literatures on distributed leadership supported the positive results that were documented in this study. Findings from this study provided empirical evidence that a distributed approach in leadership is able to influence the outcome of low-carbon city agenda. The findings concurred with studies that suggest the potentially positive effects of distributed leadership on goal achievement (e.g., [98-101]) and also on improved organizational outcomes (e.g., [72,102-105]).

Leadership in the low-carbon city agenda is a shared and collaborative process of mobilizing people towards the achievements of a common goal. The collaborative process emphasis on the 
participation of the community and thrives on a strong network of interdependent relationships [42-47]. In such collaboration, informal influence may be more important than formal power [105].

Distributed leadership is enacted not only through the behavior of leaders but also through the collaboration structures and range of processes and activities. This study has demonstrated that a distributed leadership must be nurtured through organizational cultures that emphasis on cooperation and teamwork [106] and organizational-wide consensus among members around a set of shared assumptions, values and beliefs [107]. Such organizational cultures are important in creating consistency in perceptions, interpretations and actions of organizational members, and foster unity of purpose and action [108]. Literatures have often cited organizational culture as the main reason for the failure in implementing organizational change programs (e.g., $[109,110])$. In our study, an officer from the lead agency commented that it is nearly impossible to nurture and maintain such organizational culture because the members are always changing. He stated, "90\% of the community population are government servants who are constantly transferred to and from other locations. In addition, the residents' association committees are replaced after a term of two years causing difficulty in maintaining an effective network."

We found that a dispersed and inclusive leadership positively affect the effectiveness of the low-carbon lifestyle programs. Our findings corroborate findings by Sammons et al. [69] who suggest that greater involvement in leadership practice is associated with better organizational performance and outcomes. Our findings suggest that providing leadership opportunities and openness to contribution of views and ideas will accelerate the drive towards realizing a low-carbon city. This concurs with Hargreaves [111] who asserts that 'a network increases the pool of ideas on which any member can draw and their networks extend and enlarge the communities of practice with enormous potential benefits' [111] (p. 9). Hence, leadership in the low-carbon community agenda should be inclusive and accessible to all people with the motivation and commitment to action.

Multiple leaders are valuable because the knowledge and issues concerning the new lifestyle paradigm can become too complicated for only a few leaders to understand [93]. Allowing people from different degrees of expertise to take up leadership roles will help to smooth the diffusion process. This suggests that the emphasis on the local authority as the primary change agent in the low-carbon city agenda should be refocused to include other leadership sources or agents at relatively lower levels in the hierarchy. This is particularly important because RAC chairmen and RAC committee members are influential opinion leaders in the community thus could be effective agents in influencing others to adopt low-carbon lifestyle. As the lead agency, the local authority is in a strong position to provide leadership due to its position of authority, but equally important, however, is to provide opportunities and encourage other members which include community leaders and other potential leaders to take part in leading. Empowerment and facilitating access for all members [112] to the agenda are central in cultivating trust and commitment to the collaboration. This can be carried out by creating specific leadership activities or processes that involve team members in the collaboration. Another approach is to invest in capacity building for members. Leadership capacity building policies in the low-carbon city initiatives need to focus on strategies that emphasis on building commitment to the low-carbon city agenda particularly strategies to enhance the perception of a common vision, shared responsibilities, and equality in decision making. According to Avery [93], decisions need not be unanimous but can be based on consensus. Additionally, accountability and responsibility should be shared as well.

Although our findings indicate that distributed leadership is practiced at moderate level in the low-carbon initiative, we found that the leadership is more prominently characterized as authorized distributed leadership. This characterization of leadership is described as not a very dynamic or necessarily productive one in regard to sustained activity [76] and is associated with a culture of "contrived collegiality" [113] where collaborative working relationships are not spontaneous, voluntary and unpredictable but can be characterized on the contrary as administratively regulated and controlled, compulsory, implementation-oriented (putting into practice what others have decided and designed). Perhaps what is delegated to team members (or RACs) was often not leadership but 
instead management or administrative functions [114]. According to Hargreaves [113], contrived collegiality does not contribute to further development of team member's leadership.

Our findings also concur with observations by Day et al. [115] that distributed leadership where it went beyond routine delegation, cultivated a sense of ownership and agency. We noted that community leaders are eager to initiate and lead their own pro-environmental programs such as forming environmental teams in promoting pro-environmental behaviors in their communities. Utilizing their close contact with members of their community, environmental teams will be important drivers for the effective implementation of low-carbon lifestyle campaigns and programs. These groups of individuals can share knowledge and experiences, propose ideas on how to enhance the adoption of low-carbon practices and provide support to community. The teams can play a role in the development of environmental policies, targets and action plans that involve their locality. According to Middlemiss and Parrish [37] grassroots initiatives drawn on the capacity of their community can be useful to break current social boundaries and create new capacities for social change. The current research findings also suggest a need for low-carbon lifestyle promotional programs to be designed according to the contexts within the communities. Establishing meaningful dialogues within the communities, between citizens and government agencies, and also involving other related bodies is important in solving the many and inter-related issues. Also, frequent community engagements and open communications may help in cultivating ownership and curtail fervent resistance to change. According to Kaplan [116], individuals are effectively empowered to create behavior change when they are clearly informed that their individual actions can significantly make a difference in the community.

\section{Conclusions}

Although the design of this study do not allow generalization and suggestion of causal effects, the implication of the results to research and practices are quite significant. The findings of the present study contribute to a better understanding of the influence of leadership in the adoption of a low-carbon lifestyle. The present study has examined the roles of grassroots leaders in diffusing and implementing organization's vision in the communities. Rather than focusing on leaders, or top leadership team as the primary change agents, we highlighted the role of followers in the complex processes involved in diffusing any new idea, throughout an organization or a community. Findings from study suggest that the emphasis on top leaders as the primary change agents in the green city agenda should be refocused to include other leadership sources or agents at relatively lower levels in the hierarchy. The findings also indicated that grassroots leaders have different needs and perceptions on how leaders influence them. Additionally, the findings suggest that grassroots leaders were differently affected by each dimension of distributed leadership, thus they also differed in their receptivity to a leader's ideas and potential influence. Even more so, findings from the present study emphasized the importance of distributing leadership roles to committee members in formulating and leading such programs at community level or perhaps at a higher level. Hence, committee members should be roped in through engagements and open communication channels and given clear instructions on how to lead low-carbon programs in their communities.

In this study, we developed and empirically tested a hypothesized model that examined the relationship between distributed leadership as perceived by a group of leaders situated at a lower position in the organization's hierarchy and their adoption of the new lifestyle. We have empirically demonstrated that a distributed approach in leadership is able to enhance the outcome of the low-carbon city agenda. Using the framework of distributed leadership, our findings suggest that to perform as a holistic system, the low-carbon city framework must align goals, coordinate processes and resources, and include multiple expertise. It is evident from the findings that an organizational culture that facilitate multiple sources of leadership may contribute to the effectiveness of distributed leadership practices in propelling the low-carbon city agenda. While the program design targets the community citizens, agencies must first focus on their leaders who will be the communication channels or agents tasked to sell the idea. Evidence here suggests the need to provide for leadership capacity 
building that is inclusive of all leaders in order to create an overall strong and efficient leadership team in the low-carbon city agenda. An organizational culture that is based on shared values and visions shared among all members in the organizations will be a vital source of organizational commitment.

Within the context of Putrajaya Low-carbon City Initiatives, a dispersed pattern in distributing leadership is required to enhance community engagement. Thus, this study suggests that the distribution of leadership in such community be expanded to include other potential leaders and wider range of expertise. More importantly, perception that leadership is distributed must be promoted to encourage participation by the different hierarchies in the configuration. The findings of this study is however limited to the residential community of Putrajaya. Inclusion of all communities involved in the low-carbon city network such as the business community, civil servant community, and government agencies would perhaps provide a more complete assessment.

Acknowledgments: The authors would like to thank very much community leaders who have participated in this study as well as the city council of Putrajaya.

Author Contributions: The research was proposed and conducted by Azalia Mohamed. The research structure was discussed between Zelina Zaiton Ibrahim, Abu Daud Silong, Ramdzani Abdullah and Azalia Mohamed. The paper was written by Azalia Mohamed and Zelina Zaiton Ibrahim.

Conflicts of Interest: The authors declare no conflict of interest.

\section{References}

1. IPCC. Summary for policymakers. Intergovernmental Panel on Climate Change. In Climate Change 2013: The Physical Science Basis. Contribution of Working Group I to the Fifth Assessment Report of the Intergovernmental Panel on Climate Change; Stocker, T.F., Qin, D., Plattner, G.K., Tignor, M., Allen, S.K., Boschung, J., Nauels, A., Xia, Y., Bex, V., Midgley, P.M., Eds.; Cambridge University Press: Cambridge, UK; New York, NY, USA, 2013.

2. Pittock, A.B. Climate Change: Turning up the Heat; CSIRO Publishing: Collingwood, Australia, 2005.

3. Diffenbaugh, N.S.; Field, C.B. Changes in ecologically critical terrestrial climate conditions. Science 2013, 341, 486-492. [CrossRef] [PubMed]

4. Pittock, A.B. Climate Change: The Science, Impacts and Solutions; CSIRO Publishing: Collingwood, Australia, 2009.

5. Cook, J.; Oreskes, N.; Doran, P.T.; Anderegg, W.R.L.; Verheggen, B.; Maibach, E.W.; Carlton, J.S.; Lewandowsky, S.; Skuce, A.G.; Green, S.A.; et al. Consensus on consensus: A synthesis of consensus estimates on human-caused global warming. Environ. Res. Lett. 2016, 11, 1-7. [CrossRef]

6. Lewis, S.C.; Karoly, D.J. Anthropogenic contributions to Australia's record summer temperatures of 2013. Geophys. Res. Lett. 2013, 40, 3705-3709. [CrossRef]

7. Schipper, L.; Bartlett, S.; Hawk, D.; Vine, E. Linking lifestyle and energy use: A matter of time? Ann. Rev. Energy 1989, 14, 273-320. [CrossRef]

8. Lutzenhiser, L. A cultural model of household energy consumption. Energy 1992, 17, 47-60. [CrossRef]

9. Lutzenhiser, L.; Hackett, B. Social stratification and environmental degradation: Understanding household $\mathrm{CO}_{2}$ production. Soc. Probl. 1993, 40, 50-73. [CrossRef]

10. Capstick, S.; Lorenzoni, I.; Corner, A.; Whitmarsh, L. Prospects for radical emissions reduction through behavior and lifestyle change. Carbon Manag. 2014, 5, 429-445. [CrossRef]

11. Allan, C.; Kerr, S.; Will, C. Are We Turning Brighter Shade of Green? The Relationship between Household Characteristics and Greenhouse Gas Emissions from Consumption in New Zealand; Motu Economic and Public Policy Research: Wellington, New Zealand, 2015.

12. Gupta, P.; Dutta, M. Trends in per capita household expenditure and its implications on carbon emissions in developed versus developing countries. Int. J. Manag. Soc. Sci. 2015, 4, 81-92.

13. Liu, W.; Oosterveer, P.; Spaargaren, G. Promoting sustainable consumption in China: A conceptual framework and research review. J. Clean. Prod. 2015. [CrossRef]

14. Martinez, K.E.; Schor, J.B.; Abrahamse, W.; Alkon, A.H.; Axsen, J.; Brown, K.; Shwom, R.L.; Southerton, D.; Wilhite, H. Consumption and climate change. In Climate Change and Society: Social Perspectives; Dunlap, R.E., Brulle, R.J., Eds.; Oxford University Press: New York, NY, USA, 2015; pp. 93-126.

15. Goodall, C. How to Live a Low-Carbon Life?; Earthscan: London, UK, 2007. 
16. Howell, R. It's not (just) "the environment, stupid!" Values, motivations, and routes to engagement of people adopting lower-carbon lifestyles. Glob. Environ. Chang. 2013, 23, 281-290.

17. Dietz, T.; Gardner, G.T.; Giligan, J.; Stern, P.C.; Vandenbergh, M.P. Household actions can provide a behavioral wedge to rapidly reduce US carbon emissions. Proc. Natl. Acad. Sci. USA 2009, 106, 18452-18456. [CrossRef] [PubMed]

18. Barr, S.; Gilg, A.W. Sustainable lifestyles: Framing environmental action in and around the home. Geoforum 2006, 37, 906-920. [CrossRef]

19. Barr, S.; Gilg, A.W. A conceptual framework for understanding and analyzing attitudes: Towards environmental behavior. Swed. Soc. Anthropol. Geogr. 2007, 89B, 361-379. [CrossRef]

20. Barr, S.; Gilg, A.W.; Ford, N.J. A conceptual framework for understanding and analyzing attitudes towards household waste-management. Environ. Plan. A 2001, 33, 2025-2048. [CrossRef]

21. Barr, S.; Shaw, G.; Coles, T. Times for (Un)sustainability? Challenges and opportunities for developing behaviour change policy. A case-study of consumers at home and away. Glob. Environ. Chang. 2011, 21, 1234-1244.

22. Barr, S.; Gilg, A.W.; Shaw, G. Helping People Make Better Choices: Exploring the behaviour change agenda for environmental sustainability. Appl. Geogr. 2011, 31, 712-720. [CrossRef]

23. Department for Environment, Food and Rural Affairs (DEFRA). A Framework for Pro-Environmental Behaviours; DEFRA: London, UK, 2008.

24. Whitmarsh, L.; O'Neill, S. Green identity, green living? The role of pro-environmental self-identity in determining consistency across diverse pro-environmental behaviours. J. Environ. Psychol. 2010, 30, 305-314.

25. Heiskanen, E.; Johnson, M.; Robinson, S.; Vadovics, E.; Saastamoinen, M. Low-carbon communities as a context for individual behavioural change. Energy Policy 2010, 38, 7586-7595. [CrossRef]

26. Moloney, S.; Horne, R.E.; Fien, J. Transitioning to low carbon communities-from behaviour change to systemic change: Lessons from Australia. Energy Policy 2010, 38, 7614-7623. [CrossRef]

27. Walker, G. The Role for 'Community' in Carbon Governance. Wiley Interdiscip. Rev. Clim. Chang. 2011, 2, 777-782. [CrossRef]

28. Klein, S.J.; Coffey, S. Building a sustainable energy future, one community at a time. Renew. Sustain. Energy Rev. 2016, 60, 867-880. [CrossRef]

29. Shove, E. Converging conventions of comfort, cleanliness and convenience. J. Consum. Policy 2003, 26, 395-418. [CrossRef]

30. Guy, S. Designing urban knowledge: Competing perspectives on energy and buildings. Environ. Plan. C Gov. Policy 2006, 24, 645-659. [CrossRef]

31. Kollock, P. Social dilemmas: The anatomy of cooperation. Am. Rev. Sociol. 1998, 24, 183-214. [CrossRef]

32. Lutzenhiser, L. Social and behavioral aspects of energy use. Ann. Rev. Energy Environ. 1993, 18, $247-289$. [CrossRef]

33. Jackson, T. Motivating Sustainable Consumption: A Review of Models of Consumer Behaviours and Behavior Change; The Sustainable Development Research Network: London, UK, 2005.

34. Thogersen, J. How may consumer policy empower consumers for sustainable lifestyles? J. Consum. Policy 2005, 28, 143-177. [CrossRef]

35. Eyre, N.; Flanagan, B.; Double, K. Engaging people in saving energy on a large scale: Lessons from the programmes of the Energy Saving Trust in the UK. In Engaging the Public with Climate Change: Behaviour Change and Communication; Whitmarsh, L., O’Neill, S., Lorenzoni, I., Eds.; Earthscan: London, UK, 2011; pp. 139-159.

36. Whitmarsh, L.; O’Neill, S.; Seyfang, G.; Lorenzoni, I. Carbon Capability: What Does It Mean, How Prevalent Is It, and How Can We Promote It?; Tyndall Working Paper; Tyndall Centre for Climate Change Research: Norwich, UK, 2009.

37. Middlemiss, M.; Parrish, B.D. Building capacity for low-carbon communities: The role of grassroots initiatives. Energy Policy 2010, 38, 7559-7566. [CrossRef]

38. Starik, M.; Rands, G. Weaving an integrated web: Multilevel ecologically sustainable organizations. Acad. Manag. Rev. 1995, 20, 908-935.

39. Tudor, T.; Barr, S.; Gilg, A. A tale of two locational settings: Is there a link between pro-environmental behaviour at work and at home? Local Environ. Int. J. Justice Sustain. 2007, 12, 409-421. [CrossRef]

40. Peters, M.; Fudge, S.; Sinclair, P. Mobilising community action towards a low-carbon future: Opportunities and challenges for local government in the UK. Energy Policy 2010, 38, 7596-7603. [CrossRef] 
41. Schelly, C.; Cross, J.E.; Franzen, W.S.; Hall, P.; Reeve, S. Reducing energy consumption and creating a conservation culture in organizations: A case study of one public school district. Environ. Behav. 2011, 43, 316-343. [CrossRef]

42. Skea, J.; Nishioka, S. Policies and practices for a low-carbon society. Clim. Policy 2008, 8, S5-S16. [CrossRef]

43. Burch, S. In pursuit of resilient, low carbon communities: An examination of barriers to action in three Canadian cities. Energy Policy 2010, 38, 7575-7585. [CrossRef]

44. Bulkeley, H.; Castán-Broto, V.; Maassen, A. Governing urban low carbon transitions. In Cities and Low Carbon Transitions; Bulkeley, H., Castán-Broto, V., Hodson, M., Marvin, S., Eds.; Routledge: London, UK, 2010; pp. 29-41.

45. Bulkeley, H.; Schroeder, H.; Janda, K.; Zhao, J.; Armstrong, A.; Chu, S.Y.; Ghosh, S. Cities and climate change: The role of institutions, governance and urban planning. In Proceedings of the 5th Urban Research Symposium: Cities and Climate Change-Responding to an Urgent Agenda, Marseille, France, 28-30 June 2009.

46. Aiken, G.T. Prosaic state governance of community low carbon transitions. Political Geogr. 2016, 55, $20-29$. [CrossRef]

47. Markantoni, M. Low carbon governance: Mobilizing community energy through top-down support? Environ. Policy Gov. 2016, 26, 155-169. [CrossRef]

48. Hartley, J.; Allison, M. The modernization and improvement of government and public services: The role of leadership in the modernization and improvement of public services. Public Money Manag. 2000, 20, 35-40. [CrossRef]

49. Townsend, A. Leading school networks hybrid leadership in action. Educ. Manag. Adm. Leadersh. 2015, 43, 719-737. [CrossRef]

50. Spillane, J.; Diamond, J. Distributed Leadership in Practice; Teachers College Press: New York, NY, USA, 2007.

51. Harris, A.; Leithwood, K.; Day, C.; Sammons, P.; Hopkins, D. Distributed leadership and organizational change: Reviewing the evidence. J. Educ. Chang. 2007, 8, 337-347. [CrossRef]

52. Harris, A. Distributed School Leadership: Developing Tomorrow's Leaders; Routledge: London, UK, 2008.

53. Spillane, J.; Halverson, R.; Diamond, J. Investigating school leadership practice: A distributed perspective. Educ. Res. 2001, 30, 23-28. [CrossRef]

54. Spillane, J. Distributed Leadership; Jossey-Bass: San Francisco, CA, USA, 2006.

55. Spillane, J. Distributed leadership. Educ. Forum 2005, 69, 143-150. [CrossRef]

56. Gronn, P. Distributed properties: A new architecture for leadership. Educ. Manag. Adm. 2000, 28, 317-338. [CrossRef]

57. Gronn, P. Distributed leadership as a unit of analysis. Leadersh. Q. 2002, 13, 423-451. [CrossRef]

58. Harris, A. Distributed leadership: Current evidence and future directions. J. Manag. Dev. 2011, 30, $20-32$.

59. Bennett, N.; Wise, C.; Woods, P.A.; Harvey, J.A. Distributed Leadership: A Review of Literature; National College for School Leadership: Manchester, UK, 2003.

60. Hulpia, H.; Devos, G.; Keer, H.V. The relation between school leadership from a distributed perspective and teachers' organizational commitment: Examining the source of the leadership function. Educ. Adm. Q. 2011, 47, 728-771. [CrossRef]

61. Spillane, J.P.; Halverson, R.; Diamond, J.B. Towards a theory of leadership practice: A distributed perspective. J. Curric. Stud. 2004, 36, 3-34. [CrossRef]

62. Harris, A. Distributed leadership: Friend or foe? Educ. Manag. Adm. Leadersh. 2013, 41, 545-554. [CrossRef]

63. Graetz, F. Strategic change leadership. Manag. Decis. 2000, 38, 550-562. [CrossRef]

64. Harris, A.; Chapman, C. Leadership in schools facing challenging circumstances. Manag. Educ. 2002, 16, 10-13. [CrossRef]

65. Woods, P.A.; Bennett, N.; Harvey, J.A.; Wise, C. Variabilities and dualities in distributed leadership: Findings from a systematic literature review. Educ. Manag. Adm. Leadersh. 2004, 32, 439-455. [CrossRef]

66. Kets de Vries, M.F.R. High-performance teams: Lessons from the pygmies. Organ. Dyn. 1999, $12,66-77$. [CrossRef]

67. Copland, M.A. Leadership of enquiry: Building and sustaining capacity for school improvement. Educ. Eval. Policy Anal. 2003, 25, 375-395. [CrossRef]

68. Sammons, P.; Qing, G.; Day, C.; Ko, J. Exploring the impact of school leadership on pupil outcomes: Results from a study of academically improved and effective schools in England. Int. J. Educ. Manag. 2011, 25, 83-101. 
69. Harris, A. System improvement through collective capacity building. J. Educ. Adm. 2011, 49, 624-636.

70. Hargreaves, A. Sustainable leadership and development in education: Creating the future, conserving the past. Eur. J. Educ. 2007, 42, 223-233. [CrossRef]

71. Leithwood, K.; Mascall, B. Collective leadership effects on student achievement. Educ. Adm. Q. 2008, 44, 529-561. [CrossRef]

72. Leithwood, K.; Seashore-Louis, K.; Anderson, S.; Walstrom, K. How Leadership Influences Student Learning: A Review of Research for the Learning for Leadership Project; Wallace Foundation: New York, NY, USA, 2004.

73. Leithwood, K., Mascall, B., Strauss, T. (Eds.) Distributed Leadership According to the Evidence; Routledge: New York, NY, USA, 2009.

74. Leithwood, K.; Mascall, B.; Strauss, T.; Sacks, R.; Memon, N.; Yashkina, A. Distributing leadership to make schools smarter: Taking ego out of the system. In Distributed Leadership According to the Evidence; Leithwood, K., Mascall, B., Strauss, T., Eds.; Routledge: New York, NY, USA, 2009; pp. 223-252.

75. Gunter, H.M. Leading Teachers; Continuum: London, UK, 2005.

76. Harris, A.; Mujis, D. Improving Schools through Teacher Leadership; Open University Press: London, UK, 2004.

77. MacBeath, J. Leadership as distributed: A matter of practice. School Leadersh. Manag. 2005, 25, 349-366. [CrossRef]

78. Fitzgerald, L.; Ferlie, E.; McGivern, G.; Buchanan, D. Distributed leadership patterns and service improvement: Evidence and argument from English healthcare. Leadersh. Q. 2013, 24, 227-239. [CrossRef]

79. Harris, A. Distributed leadership: According to the evidence. J. Educ. Adm. 2008, 46, 172-188. [CrossRef]

80. Davis, M.W. Distributed Leadership and School Performance. Ph.D. Thesis, George Washington University, Washington, DC, USA, 2009.

81. Heck, R.H.; Hallinger, P. Assessing the contribution of distributed leadership to school improvement and growth in math achievement. Am. Educ. Res. J. 2009, 46, 659-689. [CrossRef]

82. Mascall, B.; Leithwood, K.; Straus, T.; Sacks, R. The relationship between distributed leadership and teachers' optimism. J. Educ. Adm. 2008, 46, 217-228.

83. Miles, M.B.; Huberman, A.M. Qualitative Data Analysis: A Sourcebook of New Methods; Sage: Thousand Oaks, CA, USA, 1994.

84. Feinberg, M.E.; Greenberg, M.T.; Osgood, D.W.; Anderson, A.; Babinski, L. The effects of training community leaders in prevention science: Communities that care in Pennsylvania. Eval. Program Plan. 2002, 25, 245-259. [CrossRef]

85. Krejcie, R.V.; Morgan, D.W. Determining sample size for research activities. Educ. Psychol. Meas. 1970, 30, 607-610.

86. Cohen, L.; Manion, L.; Morrison, K. Research Methods in Education, 5th ed.; Routledge: London, UK, 2000.

87. Singh, S. The Impact of Distributed Leadership Practices on the Functioning of Primary Schools in Johannesburgh South, South Africa. Master's Thesis, University of South Africa, Gauteng, South Africa, 2014.

88. Tabachnick, B.G.; Fidell, L.S. Using Multivariate Statistics, 5th ed.; Allyn \& Bacon: Needham Height, MA, USA, 2007.

89. Guilford, J.P. Fundamental Statistics in Psychology and Education; McGraw Hill: New York, NY, USA, 1956.

90. DEFRA. Securing the Future: The UK Government Sustainable Development Strategy; Department for Environment, Food and Rural Affairs: London, UK, 2005.

91. DEFRA. Climate Change: The UK Programme 2006; Department for Environment, Food and Rural Affairs: London, UK, 2006.

92. McColl-Kennedy, J.R.; Anderson, R.D. Impact of leadership style and emotions on subordinate performance. Leadersh. Q. 2002, 13, 545-559. [CrossRef]

93. Conger, J.A. Charismatic and transformational leadership in organizations: An insider's perspective on these developing streams of research. Leadersh. Q. 1999, 10, 45-169. [CrossRef]

94. Avery, G.S. Understanding Leadership: Paradigms and Cases; Sage: London, UK, 2004.

95. Rowe, W.G.; Canella, A.A., Jr.; Rankin, D.; Gorman, D. Leader succession and organizational performance: Integrating the common-sense, ritual scapegoating and vicious circle succession theories. Leadersh. Q. 2005, 16, 197-219. [CrossRef]

96. Berson, Y.; Shamair, B.; Avolio, B.J.; Popper, M. The relationship between vision strength, leadership style and context. Leadersh. Q. 2001, 12, 509-527. [CrossRef] 
97. Salomon, G. No distribution without individual cognition: A distributed interactionist view. In Distributed Cognition: Psychological and Educational Considerations; Salomon, G., Ed.; Cambridge University Press: New York, NY, USA, 1993.

98. Timperley, H. Distributed leadership: Developing theory from practice. J. Curric. Stud. 2005, 37, $395-420$. [CrossRef]

99. Leithwood, K.; Harris, A.; Hopkins, D. Seven strong claims about successful school leadership. Sch. Leadersh. Manag. 2008, 28, 27-42. [CrossRef]

100. Mayrowetz, D. Making sense of distributed leadership: Exploring the multiple usages of the concept in the field. Educ. Adm. Q. 2008, 44, 424-442. [CrossRef]

101. Anderson, K.D. Transformational teacher leadership in rural schools. Rural Educ. 2008, 29, 8-17.

102. Robinson, V.M.J. Forging the links between distributed leadership and educational outcomes. J. Educ. Adm. 2008, 46, 241-256.

103. Mehra, A.; Smith, B.; Dixon, A.; Robertson, B. Distributed leadership in teams: The network of leadership perceptions and team performance. Leadersh. Q. 2006, 17, 232-245. [CrossRef]

104. Hairudin, M.A.; Yangaiya, S.A. Investigating the influence of distributed leadership on school effectiveness: A mediating role of teachers' commitment. J. Educ. Soc. Res. 2015, 5, 163-174.

105. Simkins, T. Leadership in education: 'What works' or 'What makes sense'? Educ. Manag. Adm. Leadersh. 2005, 33, 9-26. [CrossRef]

106. Petty, M.M.; Beadles, N.A.; Lowery, C.M.; Chapman, D.F.; Connell, D.W. Relationships between organizational culture and organizational performance. Psychol. Rep. 1995, 76, 483-492. [CrossRef]

107. Martin, J. Organizational Culture: Mapping the Terrain; Sage Publications: Thousand Oaks, CA, USA, 2002.

108. Zammuto, R.F. Does Who You Ask Matter? Hierarchical Subcultures and Organizational Culture Assessments; The Business School, University of Colorado: Denver, CO, USA, 2005.

109. Cameron, K.S.; Quinn, R.E. Diagnosing and Changing Organizational Culture: Based on the Competing Values Framework, 3rd ed.; Wiley \& Son Inc.: San Francisco, CA, USA, 2011.

110. Linnenlueke, M.K.; Griffiths, A. Corporate sustainability and organizational culture. J. World Bus. 2010, 45, 357-366. [CrossRef]

111. Hargreaves, D. Transforming Secondary Schools through Innovation Networks; Demos: London, UK, 2003.

112. Himmelman, A.T. On the theory and practice of transformational collaboration: From social service to social justice. In Creating Collaborative Advantage; Huxham, C., Ed.; Sage Publications Inc.: Thousand Oaks, CA, USA, 1996; pp. 19-43.

113. Hargreaves, A. Changing Teachers, Changing Times Teachers' Work and Culture in the Postmodern Age; Cassell: London, UK, 1994.

114. Grant, C.; Singh, H. Passing the buck: This is not teacher leadership. Perspect. Educ. 2009, 27, 289-301. [CrossRef]

115. Day, C.; Sammons, P.; Leithwood, K.; Harris, A.; Hopkins, D. The Impact of Leadership on Pupil Outcomes: Final Report; Department of Children, Families \& Schools (DCFS): London, UK; National College of School Leadership: Nottingham, UK, 2009.

116. Kaplan, S. Human nature and environmentally responsible behavior. J. Soc. Issues 2000, 56, 491-508. [CrossRef]

(C) 2016 by the authors; licensee MDPI, Basel, Switzerland. This article is an open access article distributed under the terms and conditions of the Creative Commons Attribution (CC-BY) license (http://creativecommons.org/licenses/by/4.0/). 